\title{
Examining Total Concentration and Sequential Extraction of Heavy Metals in Agricultural Soil and Wheat
}

\author{
Mohammad Reza Rezaei Kahkha', Somaye Bagheri², Roghayeh Noori \\ Jamshid Piri', Safoura Javan ${ }^{5 *}$ \\ ${ }^{1}$ Departement of Environmental Health Engineering, Zabol University of Medical Sciences, Zabol, Iran \\ ${ }^{2}$ Department of Biostatics and Epidemiology, Faculty of Public Health, \\ Zabol University of Medical Sciences, Zabol, Iran \\ ${ }^{3}$ Department of Soil and Water Faculty of Irrigation and Drainage, University of Zabol, Zabol, Iran \\ ${ }^{4}$ Department of Health, Neyshabour University of Medical Science, Neyshabur, Iran
}

Received: 30 November 2016

Accepted: 12 December 2016

\begin{abstract}
Soil contamination by heavy metals not only directly affects soil physical and chemical properties, reduces biological activity, and reduces soil biological nutrient achievement, but also is considered a serious risk to human health by entering the food chain and environmental security through penetrating groundwater. In this study we examined the concentrations and sequential extractions of such heavy metals as iron, lead, copper, zinc, and nickel in soil and wheat in the central part of Sistan, Iran. 160 soil samples and 160 samples of wheat from 20 specified units of soil of agricultural land of central Sistan were randomly sampled. The values of iron, lead, zinc, nickel, and copper were measured using atomic absorption spectrometry according to the standard method. Average concentrations of iron, nickel, copper, zinc, and lead in terms of $\mathrm{mg} / \mathrm{kg}$, respectively, were 9,647.34, 18.56, 7.26, 19.80, and 29.90. After examination of sequential extraction, the metals' mobilities were as follows: iron $(99 \%)>$ nickel $(33 \%)>$ copper $(31 \%)>$ lead $(27 \%)>$ zinc $(6 \%)$. Wheat measurement results showed that metal accumulation in wheat grain was less than other parts. And also the comparison with the standard shows that the values of the metals in agricultural soil in the area were below the World Health Organization standard and in this sense there is nothing wrong with the health of the soil.
\end{abstract}

Keywords: heavy metal, sequential extraction, soil, wheat, Sistan

*e-mail: safoora_javan@yahoo.com 


\section{Introduction}

Soil is an important and valuable natural source. Several factors can affect soil contamination. Heavy metals due to their physiological effects on living beings in low concentrations are important. The metals, due to their toxicity, stability, and bio-aggregation, are a serious and hazardous environmental contaminant [1-2]. They have the potential to pollute soil and water and can be scattered and aggregated in plants and animals [3]. They also can increase chronic and intensified toxicity of the food chain by bio-aggregation [4]. Heavy metals also can be in different chemical forms where each form has its own mobility, availability to living beings, chemical reactions, and toxicity. Hence using heavy metals' spatial form and type of link, their availability for living beings and forms entering the environment over time can be studied [5]. In fact, heavy metals' mobility in the environment depends on their chemical form and type of link [6]. Sequential extraction method is one of the methods to understand heavy metals' values in soil and sediment.

Also, some forms of elements can enter water and affect ecosystem living beings. In other words, heavy metals' mobility and their absorption by living beings can be studied [7]. So far several studies have been conducted on total concentration and sequential extraction of heavy metals in different areas of soil. In 2002 Sterckemen et al., by evaluating agricultural land soil contaminated with eight heavy elements surrounding two fusers in D (northern France), reported that atmospheric dust caused by two plants producing lead and zinc caused the pollution of soil surrounded by lead, zinc, cadmium, copper, mercury, indium, and silver, and the correlation between elements' concentrations based on the industrial area is different [8].

In a study conducted by Kahkha et al. that examined heavy metals' values in agricultural soil and plants irrigated with urban wastewater, the results showed that lead values in three stations and in all plant species was less than the allowed limit, and in agricultural soil was higher than the allowed limit. Cadmium and zinc values in all plant species as well as agricultural soil was within the allowed range, and irrigating agricultural land with wastewater caused heavy metals' aggregation in soil and plants [9]. Honggang et al. (2010) examined heavy metals in water, soil, and plants in riparian wetlands in southern China along the Pearl River, and the results showed that values of cadmium, chromium, copper, nickel, lead, and zinc in soil were more than plants and more in plants than water. Only in lead was a correlation found between its value in soil and plants [10]. Diz (2002) conducted a study in Pennsylvania in which values of some of heavy metals and organic pollutants were compared with sediment quality standard values of Canada and the United States. According to the results, values of all heavy metals investigated were more than the minimum effect, and values of cadmium, lead, zinc, and nickel were more than likely to effect concentrations, and values of copper were less than this amount [11]. Andrade et al. (2010) examined different phases of cadmium, chromium, copper, nickel, lead, and zinc in sediments in Poxim in northern Brazil, and the results showed that Zinc had the highest amount in the exchange phase, and much chromium was found in the remaining phase. The risk assessment carried out on the metals also showed that nickel had the lowest risk ( $\mathrm{RAC}<10 \%)$ and lead had the highest level of risk (RAC $>30 \%$ ) [12].

Nemati et al. (2011) in Malaysia conducted a study on various phases of heavy metals (zinc, copper, lead, cadmium, chromium, cobalt, nickel) in Sungai Buloh River sediment, and the results showed that chromium, copper, and lead had risks lower than $10 \%$, but cobalt, zinc, and cadmium had moderate risk [13]. Castillo et al. (2011) conducted sequential extraction of heavy metals (copper, nickel, chomiumr, lead, and cadmium) in three steps using a microwave in which chromium and lead had the most part of the exchange [14]. Xiao et al. (2012) conducted sequential extraction of nickel and chromium sediments in southern China's Pearl River. In this study, the five-step extraction method was used and the effect of time on the metals was considered. Also, the effect of time on the concentration of metals has been considered [15]. Gao et al. (2012) conducted a study on sediment pollution on the shores of Bohai Bay in Taiwan, for which different concentrations and phases of cadmium, chromium, copper, nickel, lead, and zinc were measured. All the elements in the entire area (except cadmium and lead in some stations) had little mobility. However, the results showed that cadmium, due to low concentrations, is unlikely to have a negative impact on the environment [16].

The purpose of this study was to examine heavy metals' values in agriculture soil and wheat of the central part of Zabol, and also calculate the rate of availability of these metals for living beings in the area.

\section{Material and Methods}

\section{The Study Area}

Sistan-Baluchistan Province, with an area of 187,502 $\mathrm{km}^{2}$, compromises $11.5 \%$ of the country. The central part is one of Zabol parts in Sistan-Baluchistan Province, in which the majority of the population's income is from agriculture (Fig. 1).

The main source of water supply of Sistan plain is the Hirmand River. In fact, it is an area lifeline that originates from the mountains of the Hindu Kush and the highlands of Baba Yaghma 40 miles West of Kabul, Afghanistan.

\section{Sampling}

This study is descriptive cross-sectional that was conducted in 2014 on agricultural land under wheat cultivation in central Sistan. These zone are relatively far away (about $20 \mathrm{~km}$ ) from other possible sources of contamination such as human and industrial sewage of Zabol, and is unaffected by these sources. The type of soil 


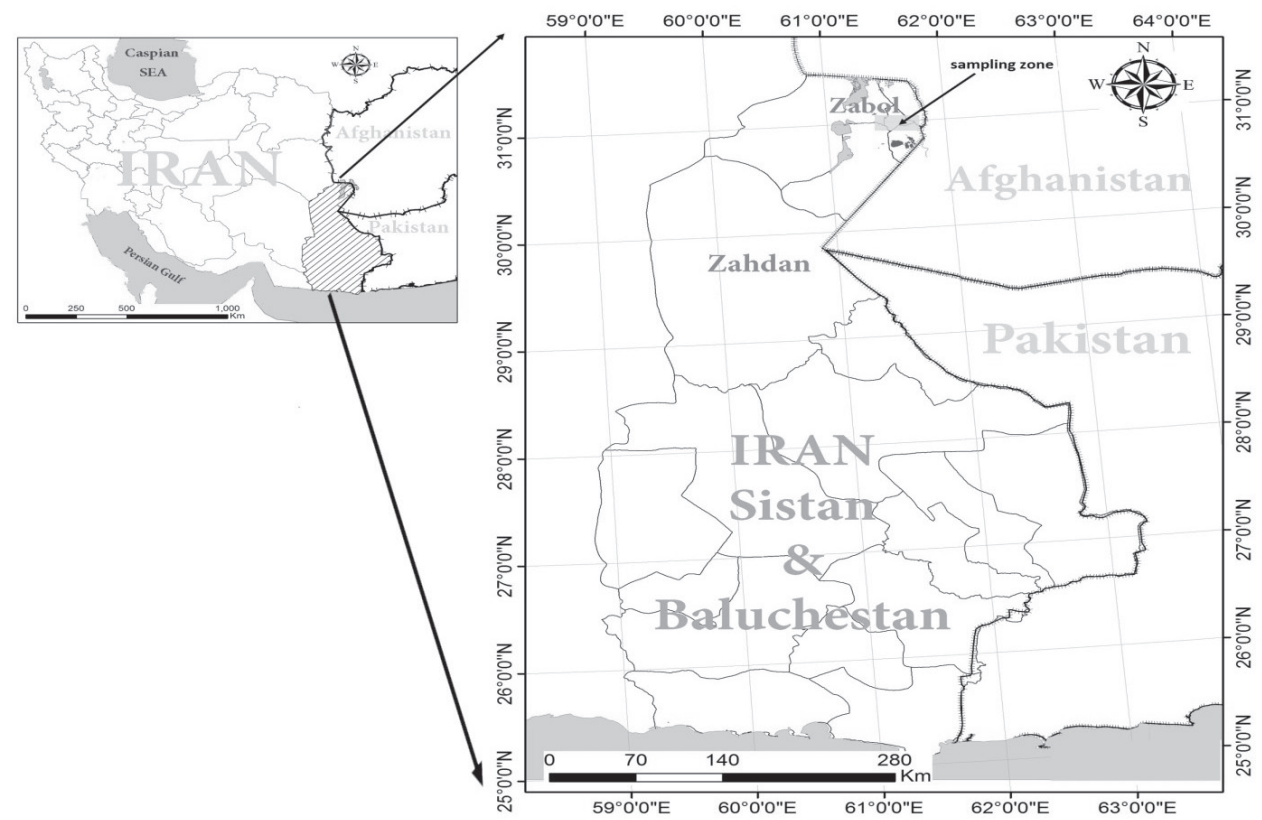

Fig. 1. Zabol map and location of sampling points.

in these places is silty loam that contains $50 \%$ or more silt and $12-27 \%$ clay, or $50-80 \%$ silt and $<12 \%$ clay. To do this sampling, 10 hectares of agricultural lands were divided into 20 units each of eight samples per unit of agricultural soil, to a depth of 0 to $20 \mathrm{~cm}$ of soil. The total number of samples was 160 . Soil samples taken were transferred into a sterile sampling container.

\section{Experiments}

\section{Determining Heavy Metals' Total Concentration}

The total concentration of heavy metals was determined as follows: First, $1 \mathrm{~g}$ of the sample was weighed and placed in a platinum crucible. Then soil was moistened with a few drops of sulfuric acid, and $5 \mathrm{ml}$ of hydrofluoric acid and $0.5 \mathrm{ml}$ of perchloric acid were added. The soil and acid mixture was placed on a heater until perchloric acid was vaporized. After cooling, $5 \mathrm{ml}$ of hydrofluoric acid was added, and the crucible was capped and placed in a sand bath under $200-225^{\circ} \mathrm{C}$ to completely dry the contents of the crucible. Then the crucible was cooled and $2 \mathrm{ml}$ of water and a few drops of perchloric acid were added and left in the sand bath to be dried and cooled. $5 \mathrm{ml}$ of hydrochloric acid $6 \mathrm{~N}$ and $5 \mathrm{ml}$ of water were added to the dried and cooled sediment. The crucible was placed on the heater until it reached the boiling point. Finally, when the remaining sediment was totally digested in hydrochloric acid, the samples were transferred to a 50-ml container and the desired volume was obtained. All analysis procedure was replicated three times and the average of results was reported [17].

\section{Determining Enrichment Factor}

The enrichment factor (EF) can be used to evaluate the environmental contamination of an area. This factor is calculated based on the amount of a given metal and its concentration in the earth's crust.

The equation below shows how EF is calculated [18]:

$$
\mathrm{EF}=((\mathrm{XFe}) \mathrm{s}) /\left((\mathrm{XFe}) \_\mathrm{c}\right)
$$

...where $\mathrm{X}$ is the concentration of a given metal (as underground reference elements), and $\mathrm{s}$ and $\mathrm{c}$ are the concentration in sediment and the earth's crust, respectively. No acceptable ranking or classification had been proposed prior to that of Sutherland in 2000, which is presented in Table 5 [19].

\section{Geo Accumulation Index}

Another common method to estimate heavy metal contamination in sediments is to measure the proportion of heavy metal concentration in sediment to the background concentration of the metal using Igeo and Ipoll indices first introduced in 1969 (Table 6) [20].

$$
\begin{gathered}
\text { Igeo }=\log 2\left(\mathrm{Cn} / 1.5^{*} \mathrm{Bn}\right) \\
\text { Ipoll }=\log 2(\mathrm{Cn} / \mathrm{Bn})
\end{gathered}
$$

...where Igeo is the geoaccumulation index or contamination intensity index, $\mathrm{Cn}$ is heavy metal concentration in the sediment, and $\mathrm{Bn}$ is background concentration of the heavy metal in the earth's crust (element concentration in shale). 


\section{Sequential Extraction}

The soil samples were sequentially extracted according to the modified Tessier method [21]. The detailed procedures are described as follows:

1. Exchangeable fraction: A total of $1 \mathrm{~g}$ of air-dried sediment sample was extracted using $20 \mathrm{ml}$ of $\mathrm{MgCl}_{2}(1 \mathrm{~mol} / \mathrm{lm} \mathrm{pH}=7)$ for $16 \mathrm{~h}$ at room temperature $\left(25-30^{\circ} \mathrm{C}\right)$ under agitation at $160 \mathrm{rpm}$ using a rotary bed.

2. Fraction binding to carbonates: The residue from step 1 was extracted using $20 \mathrm{ml}$ of $1 \mathrm{M} \mathrm{NaOAc}$ (adjusted to a $\mathrm{pH}$ of 5 with HOAc) for $5 \mathrm{~h}$ at room temperature under vigorous agitation using a rotary bed.

3. Fraction binding to hydrous Fe-Mn oxides: The residue from step 2 was extracted using $20 \mathrm{ml}$ of $\mathrm{NH}_{2} \mathrm{OH}$ and $4 \mathrm{M} \mathrm{HCl}$ in $25 \%(\mathrm{v} / \mathrm{v})$ acetic acid for in a water bath $\left(96^{\circ} \mathrm{C}\right)$ with occasional agitation.

4. Fraction binding to organic matter and sulfides: The residue from step 3 was extracted using $3 \mathrm{ml}$ of $2 \mathrm{M} \mathrm{HNO}_{3}$ and $30 \% \mathrm{H}_{2} \mathrm{O}_{2}$ (adjusted to a $\mathrm{pH}$ of 2 with $\mathrm{HNO}_{3}$ ) for $2 \mathrm{~h}$ in a water bath $\left(85^{\circ} \mathrm{C}\right)$ with occasional agitation. Subsequently, $3 \mathrm{ml}$ of $\mathrm{H}_{2} \mathrm{O}_{2}$ was added to the extracted solution and left for $3 \mathrm{~h}$ at $85^{\circ} \mathrm{C}$. Then, $15 \mathrm{ml}$ of $3.2 \mathrm{M} \mathrm{NH}_{4} \mathrm{OAc}$ in $20 \% \mathrm{HNO}_{3}$ was added to the solution and shaken continuously for $30 \mathrm{~min}$ at room temperature.

5. Residual fraction: The residue from step 4 was extracted using $8 \mathrm{ml}$ of aqua regia $\left(\mathrm{HCl}+\mathrm{HNO}_{3}\right)$.

In each step, after centrifuging for $10 \mathrm{~min}$ at $4,000 \mathrm{rpm}$, the supernatant was separated for analysis [22]. Extracted metals' total concentrations were measured using a Shimadzu AA 7000 atomic absorption spectrophotometer.

\section{Measuring the Concentration of Metals in Wheat}

In order to measure the concentration of heavy metals in different parts (root, stem, and leaf), first $1 \mathrm{~g}$ of each plant-powered sample became ash in an electric furnace at $550^{\circ} \mathrm{C}$ and after dissolving ash in hydrochloric acid the concentration of given metals in the filtrated solution was measured by atomic absorption spectrometry [23].

\section{Quality Control}

The accuracy and precision of the analysis results were checked by periodic analysis of Standard Reference Materials obtained from the Country Control Laboratory of the Agricultural Ministry. The percentage recoveries for the soil samples for iron, lead, copper, zinc, and nickel were 96.2, 94.8, 95, 95.4, and 94.7, respectively. The percentage recoveries of wheat plants for iron, lead, copper, zinc, and nickel were 96, 98, 97.1, 95.9, and 97, respectively. Blank and standard solutions were used to calibrate the instruments. The $\mathrm{R}^{2}$ values were 0.9994 , $0.9995,0.9996,0.9997$, and 0.9998 for iron, lead, copper, zinc, and nickel, respectively

\section{Results}

The results of measuring the concentration of heavy metals in agricultural soil in central Sistan showed that among studied metals, the max average concentration was for iron $(340.96 \mathrm{mg} / \mathrm{kg})$ and the min average concentration was for copper $(7.26 \mathrm{mg} / \mathrm{kg})$ so that the average concentration of metals according to Table 1 is as follows:

$$
\mathrm{Fe}>\mathrm{Pb}>\mathrm{Zn}>\mathrm{Ni}>\mathrm{Cu}
$$

By comparing the results of the concentrations of heavy metals with WHO standards (Table 2), we can observe that the average concentration of iron in studied soil is less than the global standard limit. Also, nickel concentration is equal to $18.5 \mathrm{mg}$ per $\mathrm{kg}$. By comparing nickel concentrations with WHO standards we observed that it is less than the global standard limit. Copper and zinc concentrations in studied soil were equivalent to $7.26 \mathrm{mg} / \mathrm{per} \mathrm{kg}$ and $19.86 \mathrm{mg} / \mathrm{kg}$, respectively, which are less than the global standard limit, and the average concentration of lead in agricultural soil in central Sistan is $29.909 \mathrm{mg} / \mathrm{kg}$, which is within the global standard limit.

As part of the work, different geochemical indices were calculated for grading agricultural soil contamination levels in central Sistan (Table 3).

The results of the contamination factor (cf) for heavy metals in agricultural soil in central Sistan (Table 3) and a comparison with the gradation of contamination level of sediments (Table 4) show that iron, nickel, copper, and zinc were at low contamination levels and lead in terms of this index was at medium level.

Table 1. Concentrations of trace metals in agricultural soil in central Sistan $(\mathrm{mg} / \mathrm{kg})$.

\begin{tabular}{|c|c|c|c|c|}
\hline STD & MEAN & MIN & MAX & \\
\hline 223.94 & 340.96 & 71.33 & $1,084.23$ & $\mathrm{Fe}$ \\
\hline 6.53 & 18.56 & 5.07 & 27.170 & $\mathrm{Ni}$ \\
\hline 8.07 & 7.26 & 0.78 & 29.91 & $\mathrm{Cu}$ \\
\hline 19.01 & 198.6 & 269 & 67.89 & $\mathrm{Zn}$ \\
\hline 8.50 & 29.909 & 18.75 & 54.19 & $\mathrm{~Pb}$ \\
\hline
\end{tabular}

Table 2. WHO Concentrations for trace metals in soil [24] $(\mathrm{mg} / \mathrm{kg})$.

\begin{tabular}{|c|c|c|c|}
\hline $\begin{array}{c}\text { Medium } \\
\text { pollution }\end{array}$ & Low pollution & $\begin{array}{c}\text { Severe } \\
\text { pollution }\end{array}$ & \\
\hline 3,000 & 2,000 & - & $\mathrm{Fe}$ \\
\hline 36 & 23 & 49 & $\mathrm{Ni}$ \\
\hline- & 35 & - & $\mathrm{Cu}$ \\
\hline 290 & 120 & 460 & $\mathrm{Zn}$ \\
\hline 83 & 36 & 130 & $\mathrm{~Pb}$ \\
\hline
\end{tabular}


Table 3. Different geochemical indices in agriculture soil in central Sistan.

\begin{tabular}{|c|c|c|c|c|}
\hline IPOLL & LGEO & EF & CF & \\
\hline-7.1 & - & -1 & 0.07 & $\mathrm{Fe}$ \\
\hline-1.4 & -2.0 & 0.01 & 0.37 & $\mathrm{Ni}$ \\
\hline-2.6 & -3.21 & 0.04 & 0.16 & $\mathrm{Cu}$ \\
\hline-1.82 & -2.4 & 0.02 & 0.28 & $\mathrm{Zn}$ \\
\hline-0.004 & -0.004 & 0.004 & 1.49 & $\mathrm{~Pb}$ \\
\hline
\end{tabular}

Table 4. Contamination factor classes with respect to soil quality.

\begin{tabular}{|c|c|}
\hline SOIL QUALITY & $\mathrm{CF}$ \\
\hline LOW POLLUTED & $\mathrm{CF}<1$ \\
\hline MODERATLY POLLUTED & $1 \geq \mathrm{CF} \geq 3$ \\
\hline CONSIDERABLE POLLUTED & $3 \geq \mathrm{CF} \geq 6$ \\
\hline HIGHLY POLLUTED & $\mathrm{CF}>6$ \\
\hline
\end{tabular}

Comparing the results obtained from the index Igeo (Table 4), Table 5 shows that the index of agricultural soil Ipoll Igeo and central part of Zabol in terms of heavy metals studied are completely non-polluting. By calculating Ef index for heavy metals in studied soil range (Table 3 ) and comparing with Table 5, we found that studied metals had the lowest enrichment, indicating a repulsive environment.

Comparing the results obtained from calculating the Igeo index (Table 4) with Table 5 we found that -

Table 5. EF classes with respect to soil quality [25].

\begin{tabular}{|c|c|}
\hline Enrichment at minimum level & $\mathrm{EF}<2$ \\
\hline Medium enrichment & $\mathrm{EF}=2-5$ \\
\hline Significant enrichment & $\mathrm{EF}=5-20$ \\
\hline Intense enrichment & $\mathrm{EF}=20-40$ \\
\hline Very intense enrichment & $\mathrm{EF}>40$ \\
\hline
\end{tabular}

Table 6. Igeo and Ipoll classes with respect to soil quality [20].

\begin{tabular}{|c|c|c|}
\hline Soil Quality & $\begin{array}{c}\text { Igeo and } \\
\text { Ipoll }\end{array}$ & $\begin{array}{c}\text { Igeo and } \\
\text { Ipoll }\end{array}$ \\
\hline Very highly polluted & 6 & $>5$ \\
\hline Highly to very highly polluted & 5 & $4-5$ \\
\hline Highly polluted & 4 & $3-4$ \\
\hline Moderatly to highly polluted & 3 & $2-3$ \\
\hline Moderatly polluted & 2 & $1-2$ \\
\hline Unpolluted to moderately polluted & 1 & $0-1$ \\
\hline Unpolluted & 0 & $<0$ \\
\hline
\end{tabular}

according to Ipoll and Igeo indices in agricultural soil in central Sistan - in terms of heavy metals studied, they are completely non-contaminated.

\section{The Results of Sequential Extraction of Soil}

To determine the degree of mobility, various links of heavy metals to the area soil were measured in five different phases. These phases include the following (Fig. 2).

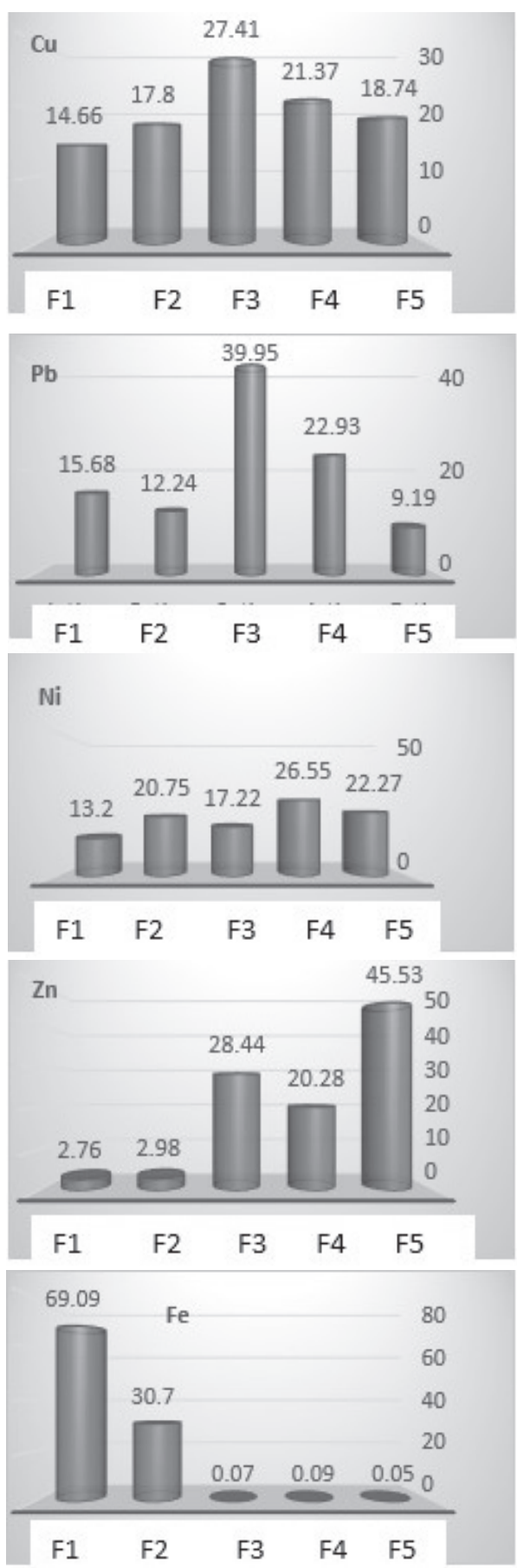

Fig. 2. Average percentage sequentially extracted of trace metals in agricultural soil in central Sistan. 
Table 7. Concentrations of trace metals in wheat in central Sistan $(\mathrm{mg} / \mathrm{kg})$.

\begin{tabular}{|c|c|c|c|}
\hline \multicolumn{3}{|c|}{ Mean \pm STD } & \\
\hline Seed & Stem & Root & Trace metals \\
\hline $0.26 \pm 0.02$ & $0.14 \pm 0.05$ & $0.15 \pm 0.13$ & $\mathrm{Ni}$ \\
\hline $1.39 \pm 0.5$ & $1.26 \pm 0.4$ & $0.92 \pm 1.18$ & $\mathrm{Zn}$ \\
\hline $0.86 \pm 0.19$ & $0.86 \pm 0.17$ & $0.56 \pm 0.2$ & $\mathrm{Cu}$ \\
\hline $0.46 \pm 0.37$ & $7.57 \pm 5.87$ & $19.75 \pm 4.23$ & $\mathrm{Fe}$ \\
\hline $0.82 \pm 4.36$ & $0.43 \pm 2.17$ & $0.87 \pm 0.61$ & $\mathrm{~Pb}$ \\
\hline
\end{tabular}

\section{The Results of Wheat}

The results of measuring concentrations of heavy metals in wheat are expressed in Table 7.

\section{Discussion}

The results for the total concentration of iron in this study indicate in Table1 that the metal is consistent with the results of Shahbazi et al., who showed that average concentrations of copper, nickel, and zinc in the study area were less than the maximum acceptable concentrations for agricultural land in other countries [26]. But mean concentration of chromium was higher than the maximum acceptable concentrations in Poland, Canada, and Australia, so we can say that the area is contaminated to some extent by chromium [27]. Also, the study results are not consistent with the results of Tabari et al., who examined the effect of irrigation by urban wastewater on the accumulation of iron, copper, and lead in forest soil (acacia), and the results of determining the concentrations of heavy metals in water samples (urban wastewater and sewage) and soil showed that urban wastewater and irrigating soil with it had high levels of the above heavy metals [28], but no nickel contamination was observed in central Sistan, so the results are not consistent with the results of Diz (2002) [11] and Harchegani (2013) [29]. In this study, lead has been obtained within the global standard limit and the value is not problematic for crops. In studies of Kahkha (2009) [9], Tabari [28], Diz [11] and Beigi [29], lead values are incompatible with the present study. Zinc values are less than the limit, which is consistent with the results of Kahkha and Shahbazi [9] and inconsistent with the results of Harchegani and Diz [11,29]. It seems that low values of heavy metals in agricultural soil in central Sistan are due to the area soil irrigation through Hirmand River water, and farmers do not use urban wastewater. Also, due to the lack of industrial plants (lack of human resources), amounts of iron, lead, nickel, zinc, and copper in soil are less than WHO standards (Table 2). Although the use of pesticides and chemical fertilizers will cause low input and accumulation of heavy metals in the soil, planning a continuous monitoring system is necessary, especially in
Helmand River water that flows from Afghanistan to Iran with no precise control over the emission of pollutants into the water in Afghanistan. The results for heavy metals are only due to the area geology, and then the area soil in terms of heavy metals studied is suitable for agricultural purposes.

Given that even if values of heavy metals obtained are less than the standard limit, regarding the link type between the metal and soil, a part of the metal in soil can be absorbed by plants. In this study, five chemical phases were examined, showing metals' availability for living beings.

The results of sequential extraction shown in Fig. 2 indicate that iron had the max percentage of exchangeable phase, about $70 \%$ is available for plants, and the minimum percentage was related to zinc. The theory that the exchangeable part in the soil is very toxic and important in terms of availability for living beings has been widely accepted [30]. The part easily enters water and through absorption enters living beings' bodies [31]. Most heavy metals entering the environment through human activities are in an exchangeable part [32].

In the carbonate phase, $30.7 \%$ is iron, $20.75 \%$ is nickel, $2.98 \%$ is zinc, $17.8 \%$ is copper, and $15.68 \%$ is lead. Studies show that heavy metals related to the carbonate phase have poor links that by a little change of the environment, especially in $\mathrm{pH}$, enter the water [22]. Therefore, regarding two first phases iron is mainly absorbed by plants in the area.

Iron sulfide and the manganese-related part is considered one of the best geochemical phases to control heavy metals' behavior in the sediment. For the part is linked to the sediment under natural conditions of the environment [33]. The link is changed by environmental changes (pH) [34]. Lead is the main part of the link (39.95\%). Also, about one-third of zinc and copper in the phase shows that the metals are not available to plants. Although the phase linked to organic materials causes a moderate limit to the sediment and metal link, it is likely that living beings can use the metals in the phase. The phase is composed of . $09 \%$ iron, $26.55 \%$ nickel, $20.28 \%$ zinc, $21.38 \%$ copper, and $23.93 \%$ lead. Heavy metals with human origin in the environment are totally introduced as inorganic compounds easily absorbed by the sediment with poor physicochemical links [35]. There is no concern about remaining metals in the phase, although the presence of an element in the phase shows that we should expect low mobility for the phase is a strong one [36]. The phase is composed of $53.45 \%$ zinc - the highest percentage. The lowest percentage is for iron.

Comparing the results with risk assessment code (RAC) classification, showing evaluation of metals' risk in the soil, showed that iron had maximum mobility. $99 \%$ of total concentration of the metal can enter the environment. Copper and Nickel are ranked No. 4 in terms of RAC, with high risk to the environment that under natural conditions more than $30 \%$ of the link can be separated by the soil. Lead risk is moderate so that the two previous metals have 
better conditions. Zinc has the lowest mobility in terms of RAC and is ranked No. 2. Classification of heavy metals measured by $\%$ is:

$$
\begin{gathered}
\operatorname{Iron}(99 \%)>\operatorname{Nickel}(33 \%)>\operatorname{Copper}(31 \%) \\
>\operatorname{Lead}(27 \%)>\operatorname{Zinc}(6 \%)
\end{gathered}
$$

- Lead concentration recommended by WHO and FAO is 0.2 .

- The nickel threshold limit in cereals has been determined at $1.63 \mathrm{mg} / \mathrm{kg}$, and nickel average concentration in wheat is less than the allowed limit, with average concentration of nickel is as seed $>$ stem $>$ root.

- Average concentration of zinc in wheat is less $t$ han value recommended by WHO and FAO $(27.4 \mathrm{mg} / \mathrm{kg})$, so zinc concentration in the samples is within the allowed limit. Zinc deficiency is one of the most common deficiencies of micronutrients in calcareous and alkaline soil. The main reason is lack of available zinc in soil. Calcareous soil has an alkaline reaction. Consequently, any plants are striving for micronutrients such as iron, zinc, copper, and magnesium.

- The maximum allowed concentration of copper in cereals based on $\mathrm{WHO} / \mathrm{FAO}$ has been reported as $3 \mathrm{mg}$ per $\mathrm{kg}$, and average copper concentration of wheat tested was less than the recommended limit.

\section{Conclusions}

Considering that in central Zabol wastewater is not used for farm irrigation, as well as due to the lack of industrial plants (absence of lead sources, etc.), values of iron, lead, nickel, zinc, and copper in area soil was less than the WHO standard. In conducted studies in industrial cities, lead and zinc concentrations - because of air pollution and fossil fuels - are more than the measured standard limit, while values of the two metals were measured less than the standard limit in this study area. Also, the availability of lead and zinc because of air pollution in industrial cities was high. In a study carried out on soil in Zabol, values of the two metals had the min availability among studied metals.

\section{References}

1. MACFARLANE G.R., BURCHETT M.D. Cellular distribution of copper, lead and zinc in the grey mangrove, Avicennia marina (Forsk.) Vierh. Aquatic Botany. 68 (1), 45, 2000.

2. DEFEW L., MAIR J., GUZMAN H. An assessment of metal contamination in mangrove sediments and leaves from Punta Mala Bay, Pacific Panama. Mar. Pollut. Bull. 50 (5), 547, 2005.

3. IOVEN E.W.S., KUCHARSKI R., SZDZUJ R. Human health risk assessment case study: an abandoned metal site in Poland. Chemosphere. 47 (5), 507, 2002.
4. AHMAD K., MEHDI Y., HAQUE R., PULAKESH M. Heavy metal concentrations in some macrobenthic fauna of the Sundarbans mangrove forest, south west coast of Bangladesh. Environ. Monit. Assess. 177 (1), 2011.

5. GHREFATA H., YUSUF N. Assessing Mn, Fe, Cu, Zn, and Cd pollution in bottom sediments of Wadi Al-Arab Dam, Jordan. Chemosphere. 65 (11), 2114, 2006.

6. VODYANITSKII Y.N., Methods of Sequential Extraction of Heavy Metals from Soils: New Approaches and the Mineralogical Control (A Review). SOIL CHEMISTRY. 39 (10), 1074, 2004.

7. CHAO T. Use of partial dissolution techniques in exploration geochemistry. Journal of Geochemical Exploration. 20, 101, 1984.

8. STERCKEMAN T., DOUAY F., PROIX N., FOURRIER H., PERDRIX E. Assessment of the contamination of cultivated soils by eighteen trace elements around smelters in the North of France. Water, Air, Soil Pollut. 135 (1-4), 173, 2002.

9. KAHKH M.R.R., KEYKHII M ., REZAIE H. Assessment of heavy metal concentratioins in soil and plants irrigated with urban sewage. Qurterly Journal of Rostamineh. 3 (2), 19, 2009 [In Persian].

10. ZHANG H., CUI B., XIAO. R., ZHAO R. Heavy metals in water, soils and plants in riparian wetlands in thePearl River Estuary,South China. Procedia Environmental Sciences. 2, 1344, 2010.

11. DIZ H.R. An Assessment of Sediment Quality in Presque Isle Bay Erie, Pennsylvania (Final Report, Department of Environmental Science \& Engineering Gannon University). 33, 2002.

12. ANDRADE PASSOS E., ALVES J., DOS SANTOS I., PATROCINIO H J., GARCIA C., SPINOLA COSTA A. Assessment of trace metals contamination in estuarine sediments using a sequential extraction technique and principal component analysis. Microche mical Journal. 96, $50,2010$.

13. NEMATI K., ABU BAKAR NK., ABAS MR., SOBHANZADEH E. Speciation of heavy metals by modified BCR sequential extraction procedure in different depths of sediments from Sungai Buloh, Selangor, Malaysia. Journal of Hazardous Materials. 192 (1), 402, 2011.

14. ALSONO CASTILLO M.L., VEREDA ALSONO A., SILES COEDERO M.T., CANO PAVON J.M., GARCIA DE TORREA A. Fractionation of heavy metals in sediment by using microwave assisted sequential extraction procedure and determination by inductively coupled plasma mass spectrometry. Microche mical Journal. 98, 234, 2011.

15. XIAO R., BAI J., GOA H., HUANG L., HUANG CH., LIO P. Heavy metals ( $\mathrm{Cr}$ and $\mathrm{Ni}$ ) distribution and fractionation in cropland soils from reclaimed tidal wetlands in Pearl River estuary, South China. Procedia Environmental Sciences. 13, 1684, 2012.

16. GAO X., TUNG C., CHEN A., Heavy metal pollution status in surface sediments of the coastal Bohai Bay. water reaserch. 46 (6), 2012.

17. PAGE A., R MILLER., KENNY D. Method of soil analysis. Part 2:Chemical and microbiological propertis.American society of Agronomy.Soil Sience Society of American. Wisconsin.USA. 1159, 1982.

18. SIYUE L., QUANFA Z. Risk assessment and seasonal variations of dissolved trace elements and heavy metals in the Upper Han River, China, Journal of Hazard Material. 181, 1051, 2010.

19. SUTHERLAND R. Bed Sediment-Associated Trace Metals in an Urban Stream, Oahu, Hawaii. Environmental Geology. 39, 611, 2000. 
20. MULLER G. Index of geoaccumulation in sediments of the Rhine River. Geo. J. 2 (3), 108, 1969.

21. URE A.M., QUEVAUVILLER P.H., MUNTAN H., GRIEPINK. Speciation of heavy metals in soils and sediments An account of the improvment and harmonization of extraction techniques undertaken under the auspices of the BCR of the emission of the European communies. International Journal of Environmental Analytical chemistry. 51, 135, 1993.

22. TESSIER A., CAMPBELL P.A., BISSON M. Sequential extraction procedure for the speciation of particular trace metal. Anal chem. 51 (7), 844, 1979.

23. WESTERMAN R.L. Soil Testing and Plant Analysis. SSSA, Madison, Wisconsin, USA., 1990.

24. MACDONALD D.D., BERGE T.A, BERGER T.A. Development and Evaluation of Consensus-Based Sediment Quality Guidelines for Freshwater Ecosystems Enviranrnental Contamination and Toxicology. 39, 20, 2000.

25. PEKEY H., Heavy metal pollution assessment in sediments of the Izmit Bay, Turkey. Environ. Monit. Assess. 123 (1-3), 219, 2006.

26. SHAHBAZI A., SOFFIANIAN A.R., MIRGHAFFARI N., EINGHLAIE M.R. Contamination Factor and Comprehensive Pollution Index (A Case Study in Nahavand City). Environment and Development Journal. 5, 2012 [In Persian].

27. KACZALA F., MARQUES M., HOGLAND W. Lead and vanadium removal from a real industrial wastewater by gravitational settling/sedimentation and sorption onto Pinus sylvestris sawdust. Bioresour. Technol. 100 (1), 235, 2009.

28. TABARI M., SALEHI A. Impact of Irrigation by Municipal Sewege on Accumulation of Heavy Metals in Soil. Journal of Enviromental Science and Technology. 13, 49, 2012 [In Persian].
29. HARCHEGANI H.B., BANITALEBI G., The Effect of Twenty-Three years of Surface Irrigation With Treated Municipality Waste Water on Soil Loadings, Transfer to wheat and Corn Grains, and Related Health Rishs of Some Heavy Metals. Journal of Water and Soil. 27 (3), 570, 2013.

30. WANG S., JIA Y., WANG S., WANG X., WANG H., LIU B. Fraction of heavy metals in shallow marin sediments from Jinnzheu Bay, China. journal of Environmental Sciences. 22 (1), 23, 2010.

31. ZEMBERYVA M., ZWAIK A., FARKASOVSKA I., sequential extraction for the speciation of some heavy metals in soils. journal of Radioanalaytical and Nuclear chemestry. 229, 67, 1998.

32. DOELSCH E., MOUSSARD G., SAINT MH. Fractionation of tropical soilborne heavy metals-Comparison of two sequential extraction procedures. Geoderma 143, 168, 2008.

33. PETERSON W., WALLMAN K., SCHROER S., Schroeder Fstudies on the adsorption of cadmium hydrous iron oxides inoxic sediments. Anatica chimica Acta. 273, 323, 1993.

34. FERRARO A., VAN HULLEBUSCH ED., ESPOSITO G., PIROZZI F. Application of an electrochemical treatment for EDDS soil washing solution regeneration and reuse in a multi-step soil washing process: Case of a $\mathrm{Cu}$ contaminated soil. J Environ Manage 163, 62, 2015.

35. GUO H., WANG W., SUN Y., LI H., AI F., XIE L., WANG $\mathrm{X}$. Ethyl lactate enhances ethylenediaminedisuccinic acid solution removal of copper from contaminated soils. J Hazard Mater 174, 59, 2010.

36. CELEBI A., SENGORUR B., KLAVE B. Human health risk assessment of dissolved metals in groundwater and surface waters in the Melen watershed, Turkey, Journal of environmental science and health, Part A: Toic/hazardous substances and environmental engineering. 49, 153, 2014. 